\title{
Stimulate at Risk Dyscalculic Pupil to Learn a Number Sequence: A Single Case Study in LINUS 2.0 Numeracy Remedial Class in Sandakan, Sabah
}

\author{
Sai Hoe Fu* \& Kin Eng Chin \\ Universiti Malaysia Sabah \\ *Corresponding Author: fikk221002@hotmail.com
}

\begin{abstract}
This study aims to explore a single case of teaching a number sequence using a new idea which is known as "drawing your hands" in order to engage at-risk Dyscalculic pupils. This research incorporates active learning which based on the cognitive constructivism theory and Feuerstein' Mediated Learning Experiences to derive a new teaching method. It was implemented at a primary school in Sandakan, Sabah. This is a qualitative study involving one mathematics teacher and one at risk Dyscalculic pupil from a national primary school. The data were collected via lesson observations, interviews, and document analyses. The finding revealed that this new teaching concept was practical to scaffold the at-risk Dyscalculic pupil to learn number sequence.
\end{abstract}

Keywords Dyscalculia, mediated learning, number sequence, active learning

\section{INTRODUCTION}

Dyscalculia is an umbrella term for various conditions that refer to developmentally based impairment or effect of brain injuries in the ability to learn and perform mathematics $[1,2,3,4]$. It is about $6 \%$ of the population is struggling with dyscalculia [5]. Supported by the report of a preliminary study for Dyscalculia which involved 91 students in three primary schools in Sabah, Malaysia showed that $5.5 \%$ of the primary school students in Sabah suffered from Dyscalculia [6]. Moreover, a study conducted by the same researcher team indicated that there is no significant gender difference in prevalence rates of Dyscalculia, but there is a significant difference between LINUS students in urban and rural schools [7].

Hannell, G. [3] also pointed out that Dyscalculic pupils are poor in number sense such as they cannot perform subitizing (recognise the small quantities without counting) and counting, slow response to give answers to mathematics questions, find it is difficult to talk about mathematical processes, have trouble remembering basic mathematics facts, symbols and procedure, sequence and confused about position and spatial organization. More precisely, [8] described that Dyscalculic pupils' main problems are they can recite the number sequence without understanding what counting really means, not appreciating the concept of cardinality, having a limited sense of quantity and numerical magnitude. Most of the educators and researchers suggested that indicated the teaching and learning activities should be explicit at every moment and break topics down into chunks; therefore the Dyscalculic pupils are easy to catch up the pace confidently using appropriate materials and visual images $[8,9,3]$. However, there is no significant research to show that which teaching method is practical to assist the at-risk Dyscalculia pupils to master the numeracy skills by connecting the content knowledge and the uses of teaching materials 
together.Therefore, this paper is a probe into the way of stimulating at risk dyscalculia pupils to learn number sequence.

\section{LITERATURE REVIEW}

The early stage of recognising a number system and to implement four arithmetic operations is to learn to count [10]. Yet, there are two significant aspects of counting - knowing the number sequence such as one, two, three, etc. and knowing the relationship between numbers and objects. The first skill involves the one to one corresponding counting principle and this involves learning the name of individual numbers and the sequence in which they happen as every number has their own unique name [11]. The second skill involves the cardinal rules in counting principles that the last number is referring to a total of a set or a group [10]. Interestingly, [10] found that counting games assist children in learning the sequence of low numbers, but this skill is not related to the knowledge of numerosity and it could be an illusion of learning [12], for example, a young learner may be able to count up to 10 without understanding that the number 10 can be related to 10 objects in a set. This means that knowing the number sequence does not confer understanding of place value and number sense. [12] suggested that teachers should use materials and visual images to encourage young learning to recognise the patterns and make a connection with numbers in order to support their long-term memory. In addition, they proposed a hypothesis that learners may show their understanding of numeracy according to their cognitive developmental stages by structuring and relate topic to topic, to construct acquired knowledge and to explain, literally each new topic [12]. Hence, I argue that it is essential to teach at risk Dyscalculic Matt Start from the basic and strengthen their foundation by learning a number sequence. This is because one of the most important domains of early number learning is the name of the numbers, a sequence of number words and the numerals [13].

The conceptual framework of this paper stands on the blending of active learning and Feuerstein' Mediated Learning Experiences to derive a new teaching method. As we know, Active learning is based on the cognitive constructivism theory and it believes that learners construct their own knowledge and consolidate or subsume with their prior knowledge by actively participating in the teaching and learning activities [14]. Active learning is about the children as needs driven, exploratory learners, using all their senses, communication modes and meta-cognitive processing to make sense of a whole new knowledge and concepts [15]. The key point of active learning is extending learners' active experience and conveys their curiosity of learning so that they can make connections between the previous knowledge and the new experiences [15].

On the other hand, Feuerstein' Mediated Learning Experiences stand on the social constructivism theory that learners learn new concepts by scaffolding to archive the learning goal easily [16]. Mediated Learning Experiences (MLE) includes a range of techniques to guide the learners' intervention with a task or challenge as a catalyst for modifying learners' thinking both cognitively and motivationally and causing the child to learn [16]. [17] indicated that there are three vital aspects of Mediated Learning Experiences (MLE): 1) mediation of intentionality and reciprocity means the "mediator" provides the learner to engage with stimuli (intentionality) and reciprocity is that responsively from the learner during the communication, 2) mediation of meaning is referring to the mediator provides a key to understanding the meaning of stimuli, 3) mediation of transcendence means that every single activity has in it the potential for bridging the ideas. After knowing the importance of number sequence in a number system, I argue that Dyscalculic pupils should undergo the process of mediation in order to gain some previous knowledge and guidance from the mediator before they can proceed to construct and consolidate their new learning skills and knowledge to extend their learning in learning a number sequence. Therefore, I proposed a teaching method "Drawing your hands" to help the at-risk Dyscalculic pupils to learn number sequence. 


\section{METHODOLOGY}

This study administrates a single case study research design to collect the relevant qualitative data. It was carried out at one of the primary schools in Sandakan District, Sabah. One remedial teacher and one at risk Dyscalculia pupil were chosen in this study. They took part in this remedial activity on a voluntary basis. This selection of teaching materials and content are highly influential to the development of pupils' understanding of the counting. Only one voluntary teacher involved in this study. The length of the study is about two weeks, the first two days was the training session to ensure the teacher (mediator) master the meaning of mediation and the following three days was preparing the learning materials and lesson plan. The second week was the implementation of the teaching session, reflection and interviews. Data were collected through observation, interview, and document analysis. The objectives of this study are to explore how "Draw your hands" help at-risk Dyscalculic pupil in learning a number sequence from one to ten and how are the teacher's perceptions about this teaching activity. Hence the research questions for this study are (1)How " Drawing your hands" help learner in learning number sequence has been implemented? (2)How did the teachers react to the new innovative teaching activity? We collected the data from a single case study and then the data were interpreted in an integrated manner in order to answer the above research questions.

\section{FINDING}

\section{Document Analysis}

Firstly, the researcher collected all the related documents such as analysis construct in portal NKRA (National Key Results Area) (see Document 1) to identify the pupil was not able to identify pre-numbers, numbers and performing counting, the OKU card (due to research ethical issues and protect the participant's authority, the OKU card will not show in this paper) to identify the at risk Dyscalculic pupil and how the teacher prepared for her lesson by presenting her daily lesson plan (see Document 2). Moreover, the researcher found that Miss $\mathrm{Z}$ just using drilling and repetition method to boost Matt in learning numeracy by interviewing Miss $\mathrm{Z}$ about her teaching approach before the study took place.

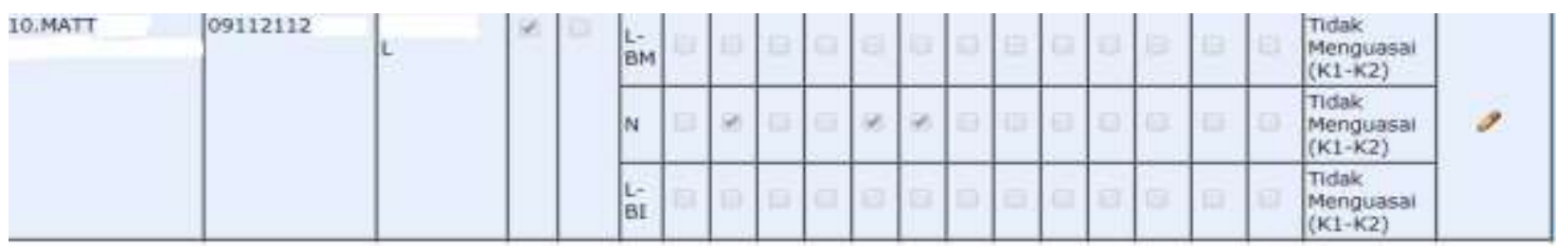

Document 1: Analysis constructs in portal NKRA 


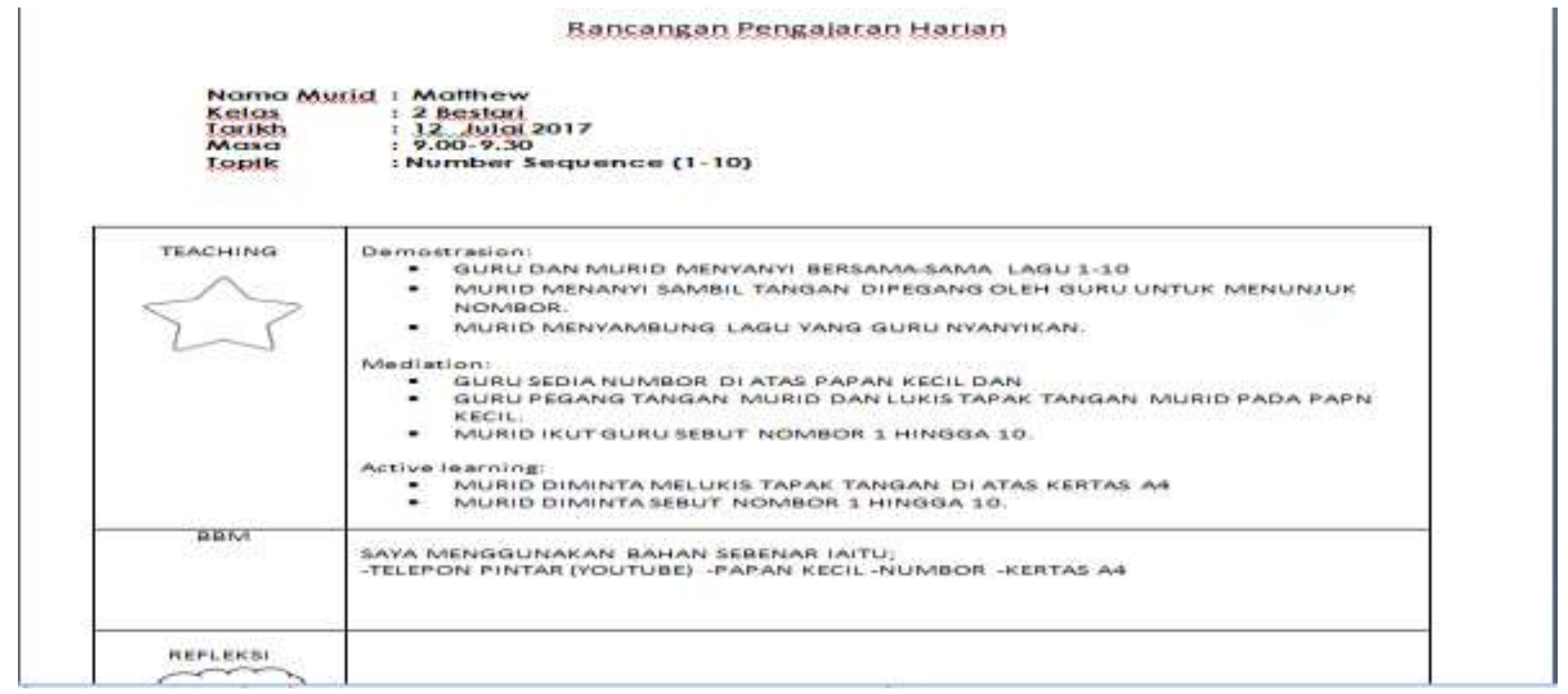

Document 2 Miss Z's daily lesson plan

\section{Observation}

For the induction set, Miss Z played a number song "one two three" as set induction. Miss $\mathrm{Z}$ sang the number song with the lyrics one to ten with the Matt. Matt was observed to be so excited and followed to sing the number song although he just can murmuring. Miss $\mathrm{Z}$ such a caring teacher that she asked Matt: "Are you ready for today's lesson?" and Matt answered Miss Z by his body language - nodded his head and I observed that Matt was a little bit nervous by holding both of his hand together. Following by teaching Matt the name of the number - one to ten verbally, Miss $Z$ arranged the number sequence using the Arabic digits and she led Matt to read after the number one to ten and pointed with the corresponding numbers as well (see figure 1). From this, the mediation of intentionality and reciprocity happens when the teacher asked Matt to look at the numbers (stimuli) intentionally to convey the knowledge of the name of the numbers and Matt was attentively giving response by reading after the name of the numbers.

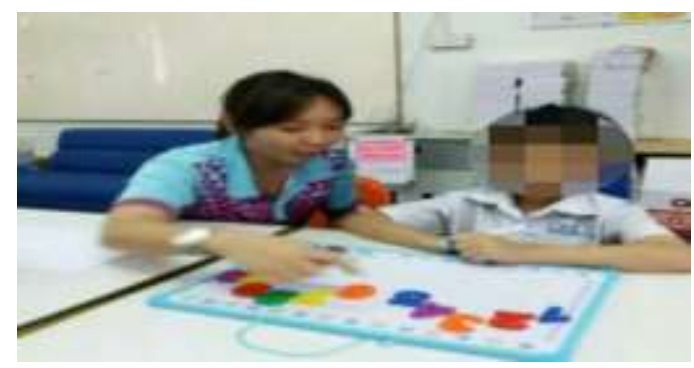

Figure 1 Miss Z lead Matt to read after number one to ten and pointed with the corresponding numbers as well

Then, Miss $\mathrm{Z}$ asked Matt to put his hand on the small board with the numeral was ready prepared in a sequence and Miss $\mathrm{Z}$ grabbed pupil's left hand to draw his right hand on the board surface using a marker pen (see figure 2). Matt felt so excited and he had been motivated to draw his own hand on the board. Once again, Miss $Z$ leads Matt to read after the name of the number - one to ten and pointed with the corresponding numeral as well. In this stage, Miss $\mathrm{Z}$ was implementing the mediation of meaning to link the name of the number - one to ten with the corresponding numeral. Surprisingly, Matt can read loudly "one, two, three ...eight " in the Malay language. Then, when Miss Z asked Matt again: "What is the 
number next to eight?" Matt looked around and paused for a while then he answered: "nine" in the Malay language. The researcher also observed that while learning a number sequence from one to ten, a learner may also learn about the number "before", "after" and "in between". Also, it is shown that the mediation of transcendence occurred that learning name of numbers will bridge the knowledge of getting known about the number before and after.

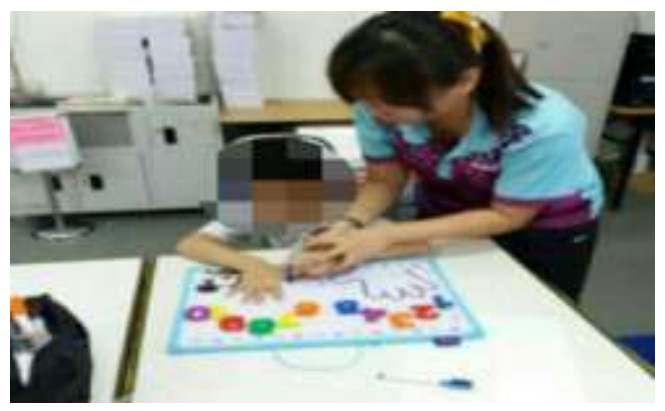

Figure 2 Miss Z grabbed Pupil's left hand to draw his right hand on the board surface using a marker pen.

After preparing Matt with the knowledge of number in words linked the numeral, Miss $\mathrm{Z}$ proceeded to teach Matt with number sequence using active learning skill. Miss $\mathrm{Z}$ demonstrated again by drawing pupil's hand. Then, Matt was asked to draw his hand by his own on a paper in order to construct his own meaning with through this practical experience (see figure 3). Miss $\mathrm{Z}$ pointed to the first finger which actually was the pinkie finger and asked: "what number is it". Matt answered "one" with confidence. Miss $\mathrm{Z}$ repeated her question with pointing the second finger (ring finger). Matt answered: "two" as well. Miss $\mathrm{Z}$ continued to ask: "How about the rest?" Matt started to recite:"one, two, three, four, five, six, seven, eight, nine, and ten" in Malay language. Amazingly, Matt can master the number sequence with linking the number word with the numerals

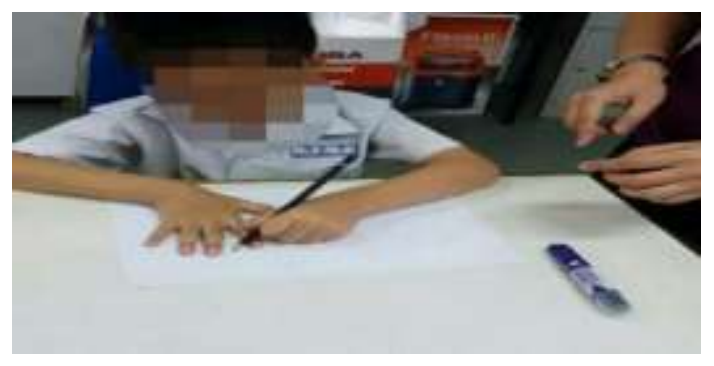

Figure 3 Matt drew his own hand on the A4 paper

After the teaching and learning sessions, Miss $\mathrm{Z}$ assessed Matt with asking him tried to write the number on top of the fingers drawing. Matt wrote one until ten with teacher's guidance, yet he wrote number 5, 7 in reflection (see figure 4). It was so great that Matt master the number sequence correctly after the remedial session. 


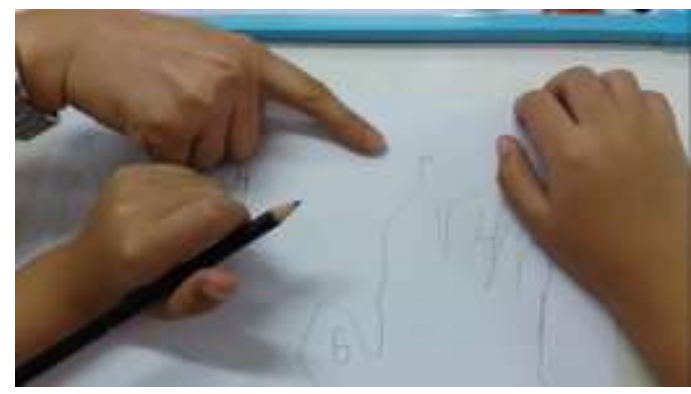

Figure 4 Matt wrote number 7 in mirror image

\section{Interviews}

From the interview's transcript, Miss Z: "I feel this new teaching method is more practical to teach number sequence for my pupil. Hmm... Matthew is a low achiever ...Hmm, I find that this teaching method can motivate his learning as I saw he is so happy during the learning and he urged to touch the learning materials as well''. She continued: "This activity break the learning contents to chunk or parts that my pupil can catch up the name of the number easily at the beginning, then proceed to connect the number word with numerals, uh...uh...at last, he can point the numbers with his finger and recite the number sequence from one to ten. I am so proud of him.... really... because he always not pays attentions in my class. In addition, she described: "Argh...I feel that this teaching method is quite different from others as I need to help him like holding his hand to draw and grab his hand to recognise the numbers. It was a great experience for me.... I think the use of the concrete material and visual images help him a lot to strengthen his memory. Of course, repetition is important for him, especially for him....ya... and at last he been asked to perform the drawing by himself and recite the number sequence...Hmm... for me, I think this activity is a good start for me to lead him to subitizing and counting in the next remediation class.

\begin{tabular}{|c|c|}
\hline Theme & Interview transcripts \\
\hline $\begin{array}{l}\text { Structured } \\
\text { Learning }\end{array}$ & $\begin{array}{l}\text { "This activity break the learning contents to chunk or parts that my pupil can catch } \\
\text { up the name of the number easily at the beginning, then proceed to connect the } \\
\text { number word with numerals." } \\
\text { "I think the use of the concrete material and visual images help him a lot to } \\
\text { strengthen his memory." } \\
\text { "Of course, repetition is important for him, especially for him....ya... and at last he } \\
\text { been asked to perform the drawing by himself and recite the number } \\
\text { sequence...Hmm... for me, I think this activity is a good start for me to lead him to } \\
\text { subitizing and counting in the next remediation class." }\end{array}$ \\
\hline $\begin{array}{ll}\text { Practical and } \\
\text { motivated } \\
\text { learning }\end{array}$ & $\begin{array}{l}\text { "I feel this new teaching method is more practical to teach number sequence for my } \\
\text { pupil. Hmm... Matthew is a low achiever ...Hmm, I find that this teaching method } \\
\text { can motivate his learning as I saw he is so happy during the learning and he urged } \\
\text { to touch the learning materials as well." } \\
\text { "uh...uh...at last, he can point the numbers with his finger and recite the number } \\
\text { sequence from one to ten." } \\
\text { "Argh...I feel that this teaching method is quite different from others as I need to } \\
\text { help him like holding his hand to draw and grab his hand to recognise the numbers. } \\
\text { It was a great experience for me...." }\end{array}$ \\
\hline
\end{tabular}




\section{DISCUSSION AND CONCLUSION}

From this case, we highlighted two issues in this discussion. There are: 1) this teaching method is unique to scaffold at risk Dyscalculic learner to learn number sequence 2) the uses of the teaching aids in this teaching methods. The teaching method proposed in this paper is unique because it is blending Active Learning and Mediated Learning Experience together. As we can notice that in the interview transcript: "Argh...I feel that this teaching method is quite different from others". The following transcripts analysis "as I need to help him like holding his hand to draw and grab his hand to recognise the numbers. It was a great experience for me..." shown that the mediation of meaning, transcendence and intentionality and reciprocity happened to scaffold at risk Dyscalculic pupil to learn the number sequence. As a parallel with [16], Mediated Learning Experiences scaffold learners to learn a new concept to obtain the learning goal by three main factors such as mediation of meaning, mediation of transcendence and mediation of intentionality and reciprocity. Moreover, the active learning happened when Miss Z assessed Matt with asking him tried to write the number on top of the fingers drawing. Matt wrote one until ten with teacher's guidance, yet he wrote number 5, 7 in reflection during the observation. Matt showed that he constructed his own knowledge in this circumstance by drawing his hand and stored the number sequence in his working memory as suggested [15] that active learning can prolong learners' active experience and cultivate their curiosity of learning so that they can make connections between the previous knowledge and the new experiences.

Generally, most of the scholars found that pupils better understand maths when they use concrete examples [18, 19, 20]. However, [21] have argued that the use of real objects do not guarantee the students to understand the mathematics concept and connect to the abstract symbols. Although real objects do not teach, application of real object in a good teaching lesson can make a great difference in mathematics [22]. Therefore, as a qualified teacher should know how to choose the suitable teaching aids and the way of delivering the learning contents as well in order to support and achieve the learning outcomes. We synthesised that Miss Z implemented this teaching method systematically as her lesson plan was so organised and parallel to what she was implementing during her lesson and using appropriate teaching aids in her lesson. Miss $\mathrm{Z}$ highlighted the uses of 3D Arabic digits and drawing a hand on a small board to assist Matt to recite number sequence.

As a conclusion, this case study has described how this "Draw your hands" activity has been carried out in a remedial class providing details of the new teaching method which can impart number sequence to the at risk Dyscalculic pupil. The participant felt it was a good start about the way of conveying the knowledge by blending the mediation and active learning to scaffold the learner. She was attracted with the connection between the idea of breaking the teaching and learning activity into parts such as learning number words, link with the numerals and then proceeds to number sequence. On the other hands, Matt was motivated to learn number sequence verbally and written by observing and assessment, guided by Miss Z. At last, Matt was able to answer the assessment correctly even though he wrote the number five and number seven in mirror images. Therefore, it can be concluded that this remedial activity was practical new teaching method to assist the at-risk Dyscalculic pupil in learning number sequence. In future study, the researchers will explore this method with more students in pair or in groups to investigate how effective it is.

\section{REFERENCES}

[1] Davis, A. S. (2013). Psychopathology of Childhood and Adolescence: A Neuropsychological Approach. New York: Springer Publishing Company.

[2] Holliman, A. J. (2014). The Routledge International Companion to Educational Psychology. London: Routledge. 
[3] Hannell, G. (2013). Dyscalculia: Action Plans for Successful Learning in Mathematics (2 $2^{\text {nd }}$ ed.). Oxon, UK: Routledge

[4] Emerson, J., \&Babtie, P. (2013). The Dyscalculia Assessment(2nd ed.). London: Bloomsbury Education.

[5] Bird, R. (2009). Overcoming Difficulties with Number: Supporting Dyscalculia and Students Who Struggle with Maths. London: Sage.

[6] Wong. K.K., Pang, V., Chin. K.E, \& Tan, C. K. (2016). Prevalence Rate of Dyscalculia According to Gender and School Location in Sabah, Malaysia. 7th International Conference on University Learning and Teaching (InCULT 2014) Proceedings, 91-100.

[7] Wong. K.K., Pang, V., Chin. K.E, Tan, C. K., Lee, K. W.,Lay, Y. F. (2014).A Preliminary Study for Dyscalculia in Sabah,Malaysia. $7^{\text {th }}$ International Conference on Education in Mathematics, Science and Technology (ICEMST 2014) Proceedings, 462- 469.

[8] Bird, R. (2017). Dyscalculia Toolkit: Supporting Learning Difficulties in Maths. London: Sage Publications.

[9] Emerson, J., \&Babtie, P. (2014). The Dyscalculia Solution: Teaching Number Sense. London, UK: Bloomsbury Education.

[10] Butterworth, G., \& Harris, M. (2016). Principles of Developmental Psychology: an Introduction. New York: PSYCHOLOGY Press.

[11] Johnson, A., Tipps, S., \& Kennedy, L. M. (2016). Guiding Children's Learning of Mathematics. Boston, MA: Cengage Learning.

[12] Chinn, S., \&Snowling, M. (2004). Trouble with Maths: a Practical Guide to Helping Learners with Numeracy. London: RoutledgeFalmer.

[13] Thompson, I. (2010). Teaching and Learning Early Number. Maidenhead: Open University Press.

[14] Anderson, M., \& Silva, S. D. (2007). Active Learning. Sedbergh, Cumbria: Me-and-Us.

[15] Vickery, A. (2014). Developing Active Learning in the Primary Classroom. Los Angeles, CA: SAGE.

[16] Feuerstein, R., \&Lewin-Benham, A. (2012). What Learning Looks Like: Mediated Learning in Theory and Practice, $K$-6. New York, NY: Teachers College Press.

[17] Mentis, M. T., Dunn-Bernstein, M. J., \& Mentis, M. (2008). Mediated Learning: Teaching, Tasks, and Tools to Unlock Cognitive Potential. Thousand Oaks, CA: Corwin Press.

[18] Jorgensen, R., \& Dole, S. L. (2011). Teaching Mathematics in Primary Schools(2nd ed.). Crows Nest, N.S.W.: Allen \& Unwin.

[19] Reys, R. E., Lindquist, M., Lambdin, D. V., \& Smith, N. L. (2014). Helping Children Learn Mathematics(11th ed.). Milton, QLd: John Wiley \& Sons Australia, Ltd.

[20] Lake, J. (2009). Math Memories You Can Count On: A Literature-Based Approach to Teaching Mathematics in The Primary Classrooms. Markham, Ont.: Pembroke.

[21] Balter, L. \&Tamis-Lemonda, C. (2006). Child Psychology: A Handbook of Contemporary Issues, $2^{\text {nd }}$ Edition. New York: CRC Press.

[22] Puchner, L., Taylor, A., O'donnell, B. \& Fick, K. (2008). Teacher learning and mathematics manipulatives: A collective case study about teacher use of manipulatives in elementary and middle school mathematics lessons. School Science and Mathematics, 108 (7), 313--325. 